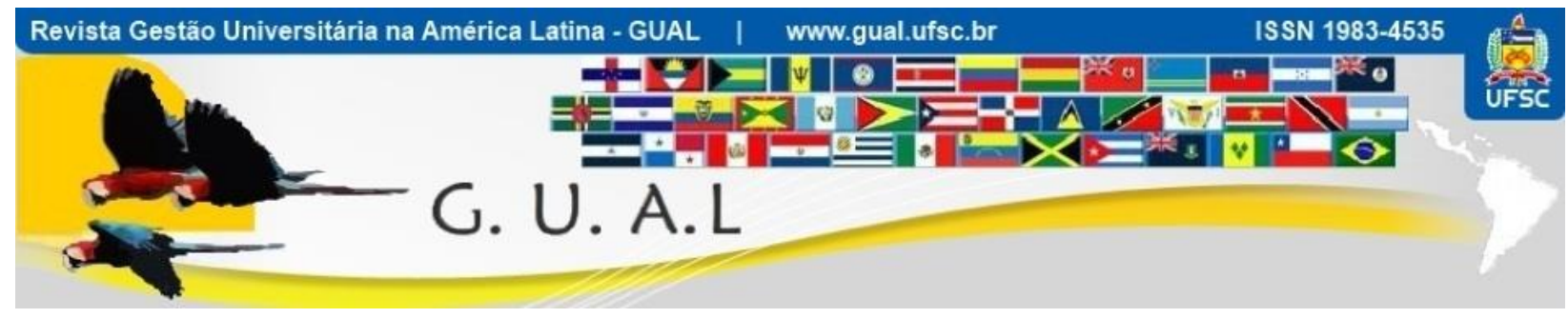

DOI: http://dx.doi.org/10.5007/1983-4535.2014v7n3p206

\title{
MUDANÇA ESTRATÉGICA E PROCESSO DE INSTITUCIONALIZAÇÃO EM UMA UNIVERSIDADE: $O$ DESENVOLVIMENTO DE ESQUEMAS INTERPRETATIVOS ENTRE OS GESTORES
}

\author{
STRATEGIC CHANGE AND INSTITUTIONALIZATION PROCESS AT A \\ UNIVERSITY: THE DEVELOPMENT OF INTERPRETIVE SCHEMES AMONG \\ MANAGERS
}

Fernando Colares Palacios, Doutor Universidade da Amazônia - UNAMA e Universidade do Estado do Pará - UEPA fac.palacios@gmail.com

Recebido em 11/dezembro/2013

Aprovado em 01/agosto/2014

Sistema de Avaliação: Double Blind Review

Esta obra está sob uma Licença Creative Commons Atribuição-Uso. 


\title{
RESUMO
}

O objetivo da pesquisa foi identificar e analisar ideias, valores e crenças presentes nos processos cognitivos dos gestores de uma nova unidade universitária em processo de implantação de uma nova estratégia. A partir de questionamentos sobre as dimensões da mudança propostas por Mintzberg et al. (2006), é avaliado o desenvolvimento de esquemas interpretativos capazes de comprovar ou não o início de um processo de institucionalização. A coleta de dados deu-se por meio de entrevistas semi-estruturadas com os gestores de nível médio, observação não participante e análise documental. A pesquisa caracteriza-se como um estudo de caso, com perspectiva de análise transversal e abordagem descritivo-qualitativa, sendo o foco, o processo de mudança estratégica em uma universidade pública brasileira Os resultados evidenciaram a importância da análise dos esquemas interpretativos dos dirigentes para compreender o nível de institucionalização de dado projeto. Também se constataram práticas incongruentes com o projeto da nova unidade e que podem comprometer a efetiva implementação da estratégia formulada.

Palavras:chave: Universidade. Mudança Estratégica. Processo de Institucionalização.

\begin{abstract}
The objective of the research was to identify and analyze ideas, values and beliefs present in the cognitive processes of the managers of a new university unit deployment of a new strategy. From questions about the dimensions of change proposed by Mintzberg et al.. (2006), is rated the development of interpretive schemes able to prove the beginning of a process of institutionalization or not . The data was collected by means of semi - structured interviews with mid-level managers, non-participant observation and document analysis. The research is characterized as a case study with prospect of cross - examination and descriptive qualitative approach, with the focus on the process of strategic change in a brazilian public university The results highlighted the importance of analyzing the interpretive schemes of the leaders to understand the level of institutionalization of the given project. Also found inconsistent practices with the design of the new unit and that can compromise the effective implementation of the formulated strategy.
\end{abstract}

Keywords: University. Strategic Change. Process of Institutionalization. 


\section{INTRODUÇÃO}

A melhor compreensão de como ocorre o processo de mudança estratégica em universidades levou a buscar responder questões formuladas anteriormente por outros autores, mas que ainda exigem maior aprofundamento. Por exemplo, Holm (1995) ao considerar o paradoxo central da nova teoria institucional questiona: Como podem os atores mudar instituições se suas ações, intenções e racionalidades são condicionadas pela instituição que desejam modificar?

A associação do estudo da mudança estratégica em universidades com a teoria institucional deve-se às características da organização universitária e do contexto no qual está inserida. Segundo a classificação ambiental de Scott (2003) trata-se de uma organização submetida tanto às pressões do ambiente técnico (relacionadas com a busca da eficiência) como do ambiente institucional (adequação às regras, exigências sociais e aspectos culturais e simbólicos).

Para analisar a mudança empreendida quando da implantação de uma nova unidade em uma universidade publica brasileira, legitimada pela sociedade e ela própria constituindose como modelo de instituição para outras universidades, optou-se por outra perspectiva de análise institucional. Nesta, procurou-se analisar o processo de institucionalização a partir do desenvolvimento dos esquemas interpretativos dos gestores envolvidos na implementação da estratégia de mudança.

Os esquemas interpretativos são o conjunto de ideias, valores e crenças que dão ordem e coerência às estruturas e sistemas de uma organização (Hinings e Greenwood, 1988). O objetivo da pesquisa é identificar por meio de entrevistas com gestores de nível médio, ou seja, os implementadores da mudança, e análise documental, quais os temas centrais (ideias, valores e crenças) que orientam suas condutas gerenciais e ao compará-los, verificar se os mesmos já constituem uma visão integrada (um esquema) e única da nova unidade, ou seja, se já configuram o desenvolvimento de um processo de institucionalização.

Para realizar este intento o artigo está dividido da seguinte forma: após esta introdução, a seção seguinte faz um breve resumo sobre a teoria institucional nas organizações, dando ênfase à perspectiva cognitiva-interpretativa, situando nesta o conceito de esquema interpretativo. Em seguida, aborda-se a universidade, aspectos que envolvem mudança e inovação em educação segundo Huberman (1973) e em organização, segundo 
Mintzberg et al. (2006). Após a exposição da metodologia empregada, apresentam-se os resultados da análise dos dados e, ao final, a conclusão.

\section{INTERPRETAÇÃO, TEORIA INSTITUCIONAL E ESQUEMAS INTERPRETATIVOS}

A origem da teoria interpretativa moderna e da visão construtivista que dela decorre pode ser remetida à obra de Max Weber e sua proposta de sociologia interpretativa, Uma das afirmações mais caracterizadoras de sua visão de mundo salienta "não ser possível conceber o conhecimento dos eventos culturais e sociais sem que este esteja fundado na compreensão da significação real contextual dos atos sociais, sempre estruturados de um modo singular e específico"(VASCONCELOS, 2004, p. 3).

Um dos principais seguidores dessa tradição da sociologia interpretativa, Alfred Schutz (1987), vai mais longe e enfatiza a importância do reconhecimento da percepção dos atores sociais afirmando que todo conhecimento, seja na vida quotidiana ou no pensamento científico, é articulado a partir de um jogo de abstrações, generalizações, formalizações e idealizações específicas para cada nível de articulação do pensamento. Nesta abordagem, “eventos sociais não podem ser tratados como 'coisas', dentro de um procedimento totalmente objetivo" (VASCONCELOS, 2004, p. 3).

Nessa linha de pensamento, o conceito de tipificação é tratado por Schutz como uma categoria epistemológica aplicada a todo o tipo de conhecimento e não só à análise sociológica. Significa que toda interpretação é fundada em experiências prévias, próprias ao sujeito ou transmitidas a ele pela família, pela educação, pelas leituras, pela influência de certos círculos sociais, etc. "Estes atos de conhecimento constituem sistemas de referências a partir dos quais os indivíduos agem e organizam as suas ações" (VASCONCELOS, 2004, p. 3). Assim, a realidade pode ser vista de formas muito diferentes dependendo destes esquemas de referência dos atores sociais.

Berger e Luckmann (2007) vão dar prosseguimento aos trabalhos de Weber e Schutz a partir da construção social do conhecimento. Na visão desses autores, a relação entre o conhecimento e sua base social é dialética, o que significa dizer que o conhecimento é um produto social e que ao mesmo tempo ele é um fator de mudança social.

O conhecimento situa-se no coração da dialética fundamental da sociedade. 'Programa' os canais pelos quais a exteriorização produz um mundo objetivo. Objetiva este mundo por meio da linguagem e do aparelho cognoscitivo baseado na 
linguagem, isto é, ordena-o em objetos que serão apreendidos como realidade. É em seguida interiorizado como verdade objetivamente válida no curso da socialização. Desta maneira, o conhecimento relativo à sociedade é uma realização no duplo sentido da palavra, no sentido de apreender a realidade social objetivada e no sentido de produzir continuamente esta realidade (BERGER e LUCKMANN, 2007, p. 94).

Para os autores, as pessoas, grupos e organizações estão envolvidos em um universo simbólico capaz de integrar um conjunto de significados, atribuindo-lhes consistência, justificativa, legitimidade; em outras palavras, o universo simbólico possibilita aos membros integrantes de um grupo uma forma consensual de apreender a realidade, integrando os significados, viabilizando a comunicação. "Existe um processo dialético entre as ideias e os processos sociais de sustentação e legitimação” (FLEURY E FISCHER, 2007, p. 18).

Weber, Schutz e Berger e Luckmann realizam uma análise social denominada de construtivista, ou seja, vêem a dinâmica das ações humanas como resultado de ações individuais intermediadas pelas representações que os indivíduos têm da realidade social.

A partir desse referencial teórico, pode-se conceituar interpretação como o processo de tradução dos eventos percebidos e focados, de desenvolvimento de modelos para compreendê-los, de desvendamento de sentido e de montagem de esquemas conceituais entre os gestores-chave. (DAFT; WEICK, 2007).

A importância do ator social na construção e validação das estruturas sociais para os autores acima destacados não condiz com a abordagem mais tradicional ou, pelo menos, mais difundida do chamado novo institucionalismo. Nesta, a noção de atores dominados culturalmente ou de agentes racionais submetidos às pressões institucionalizadas por meio de estruturas que o impedem de inovar e mudar situam a abordagem em um campo determinístico, muito restrito para a explicação de estratégia de mudança.

Machado-da-Silva, Fonseca e Crubellate (2005) apresentam uma segunda versão do novo institucionalismo, a partir de uma abordagem denominada por eles de multiparadigmática. Recuperam para tanto os conceitos de racionalidade limitada, cognição estruturada e embeddedness, aproximando pressupostos estruturalistas e funcionalistas de construtivistas e interpretativistas.

Fundamentam-se na teoria da estruturação de Giddens (1978) e nos estudos mais específicos sobre organizações de Ranson, Hinings e Greenwood (1980) para estabelecer a relação dialética entre estrutura e ação. Compreendem, então:

[...] A estrutura como mutuamente constitutiva da ação e por ela constituída, enquanto fruto de um arcabouço prescrito de regras e de procedimentos e de padrões 


\section{MUDANÇA ESTRATÉGICA E PROCESSO DE INSTITUCIONALIZAÇÃO EM UMA UNIVERSIDADE: O DESENVOLVIMENTO DE ESQUEMAS INTERPRETATIVOS ENTRE OS GESTORES \\ DOI: http://dx.doi.org/10.5007/1983-4535.2014v7n3p206}

emergentes de interação, resultantes da contínua interpretação deles na rotina da organização. Evidencia-se aí a ideia da reciprocidade [...] (MACHADO-DA-SILVA et al., 2005, p. 22).

Giddens (1989) ao desenvolver sua teoria da estruturação fundamenta-se em parte em Schutz quando este afirma que os atores empregam esquemas simbolizados (fórmulas) no decorrer de suas atividades diárias para resolver rotineiramente as situações da vida social. Dessa concepção de esquemas chega ao seu próprio conceito:

Os modos de tipificação incorporados aos estoques de conhecimento dos atores, aplicados reflexivamente na sustentação da comunicação, que permitem a conversão dos significados inerentes às estruturas em comunicação nos processos de interação (GIDDENS, 2003, p. 23).

Para Bartunek (apud CRUBELLATE, 2004, p. 94) esquema interpretativo "é um conceito similar a significados compartilhados, visão de mundo, crença ou mesmo cultura organizacional". Parte do pressuposto de que as experiências vividas podem ser entendidas de múltiplas formas. Segundo Machado-da-Silva, Fonseca e Fernandes (1999, p. 5), “entende-se por esquemas interpretativos o conjunto de ideias, valores e crenças que dá ordem e coerência às estruturas e sistemas de uma organização".

A conceituação de valores e crenças, segundo Sproull (1981), é apresentada a seguir:

\footnotetext{
Valores são concepções racionalizadas sobre o que é desejável em termos de cursos de ação. Os valores se formam a partir de entendimentos apreendidos e codificados pelos indivíduos e compartilhados pelo grupo social. Já as crenças constituem representações mentais de relacionamento entre objetos, propriedades ou ideias (apud COCHIA e MACHADO-DA-SILVA, 2004, p. 15).
}

A existência de poucos valores e crenças comuns entre os dirigentes de uma nova unidade universitária pode significar um processo de institucionalização de estruturas e processos ainda em desenvolvimento. Analisar esse conjunto pressupõe compreender quais as atividades priorizadas pelos gestores e que, de alguma forma, representam suas interpretações do mundo. Para tanto, é preciso relacioná-las com a temática de mudança e inovação no contexto universitário brasileiro e, de forma mais específica, com o projeto estratégico da nova unidade, aqui entendido como seu projeto acadêmico-organizacional.

\section{MUDANÇA, INOVAÇÃO E UNIVERSIDADE}

Segundo Huberman (1973), a ideia de mudança em educação pressupõe um processo lento, pois implica, externamente, em mudanças no âmbito da sociedade quase sempre fora do controle das organizações educacionais; e, internamente, implica em processo de assimilação, 
adoção de novas ideias e práticas, e em processo de acomodação, adaptação de estruturas anteriores a estas novas ideias e práticas. Já a inovação é o processo resultante de uma mudança planejada, “é um aprimoramento mensurável, deliberado, durável e pouco suscetível de produzir-se com frequência" (HUBERMAN, 1973, p. 15).

A universidade brasileira estruturou-se seguindo um modelo único de indissociabilidade de ensino, pesquisa e extensão, sendo esta uma orientação externa, emanada da legislação (Constituição Federal e Lei de Diretrizes e Bases -1996) e dos órgãos centrais do Governo Federal, em especial, o Ministério da Educação (MEC). Apesar da propalada indissociabilidade, pesquisas têm comprovado ser o ensino a atividade principal de grande parte das universidades brasileiras, seguindo um modelo denominado internalista (Stankiewicz, apud RODRIGUES et al., 2006). Segundo este modelo, "a classificação geral do conhecimento humano, também responsável pela geração das profissões, tem determinado a estrutura acadêmica das universidades em departamentos acadêmicos" (RODRIGUES et al., 2006, p. 3), sendo os departamentos os responsáveis finais pelo cumprimento das metas e objetivos da universidade.

O que pode melhor caracterizar este aspecto do contexto da organização universitária, no âmbito da teoria organizacional, são dois mecanismos de mudança isomórfica institucional: o isomorfismo coercitivo, que provém da influência política e do problema da legitimidade, e o isomorfismo normativo, associado à profissionalização (DIMAGGIO; POWELL, 2007).

Isomorfismo coercitivo (leis, valores e crenças) e isomorfismo normativo (elevado grau de independência de departamentos e professores) caracterizam a organização universitária brasileira, dando a ela certo imobilismo estrutural e dificuldades em construir projetos acadêmicos inovadores e integrados pela diversidade que a compõe.

Em função do crescimento das pressões por mudança, oriundas dos diversos segmentos da sociedade e do interior da própria universidade, a universidade se encontra, atualmente, mais propensa a investir em projetos estratégicos inovadores com o intuito de garantir sua relevância social. Mas o que seria o projeto estratégico em uma organização educacional como a universidade?

Para Canário, "a estratégia materializa-se num projeto educativo, próprio de cada estabelecimento de ensino, com diferentes níveis de profissionalização" (CANARIO, 1992, p. 185). Projeto educativo ou projeto político-pedagógico (PPP) como é mais conhecido no 
Brasil, é proposto, segundo Rangel (2002), como associação entre uma concepção de ensino, pautada em senso de responsabilidade social, uma concepção de sujeito humano, contextualizado no processo de transformações histórico-sociais, e uma avaliação das condições necessárias para a formação de egressos capazes de um desempenho satisfatório, aptos a contribuir para a intervenção social e interessados na superação de problemas.

O PPP, na visão de Demo (1995), é um desafio que requer o estabelecimento de condições propícias, de discussão criativa e crítica em torno do assunto, incluindo-se diretrizes de apoio. Para que ele não se transforme em um simples ato formal e obrigatório, a revisão do PPP deve possibilitar uma reflexão não apenas no nível micro (disciplinas, conteúdos etc.), mas também ao nível macro (estrutura da organização e do curso, concepções filosóficas sobre conhecimento, sobre ensino-aprendizagem, sobre o universo do trabalho).

Pode-se acrescentar nessa perspectiva o papel do gestor acadêmico para a efetiva implantação de um PPP construindo-se um sistema de liderança pautado em ações que impliquem o envolvimento pessoal da direção, a promoção de desempenho elevado, a manutenção do clima de aprendizagem, a criação de estrutura organizacional e sistema gerencial e a revisão periódica dos resultados.

Para a efetiva implementação do processo de mudança em organizações educacionais, os processos isomórficos não são suficientes para a sua explicação. Pois, entende-se como Lima (2008, p. 24) que:

[...] As organizações são sempre as pessoas em interação social, e porque os atores escolares dispõem sempre de margens de autonomia relativa, mesmo quando a autonomia das escolas não se encontra juridicamente consagrada [...]. Os atores escolares não se limitam ao cumprimento sistemático e integral de regras dadas $a$ priori, possuem capacidade estratégica de aplicarem seletivamente as regras disponíveis e mesmo de inventarem e construírem novas regras.

A esse quadro teórico próprio do campo educacional pode-se agregar a visão organizacional de Mintzberg et al. (2006) quando por meio do "cubo da mudança" (figura 1), apresentam as duas principais dimensões da mudança organizacional. Do lado esquerdo, a mudança está relacionada à estratégia, à direção seguida pela organização e, do lado direito, está relacionada à organização, às condições na qual ela se encontra. Para os autores, as duas dimensões devem ser consideradas em um processo de mudança organizacional. Salientam ainda, que mudar uma visão ou uma estrutura sem mudar mais nada "é tolo, apenas um gesto vazio" e que mudanças sérias na organização incluem o cubo inteiro: estratégia e organização, desde a mais conceitual até a mais concreta, informalmente e também formalmente. 


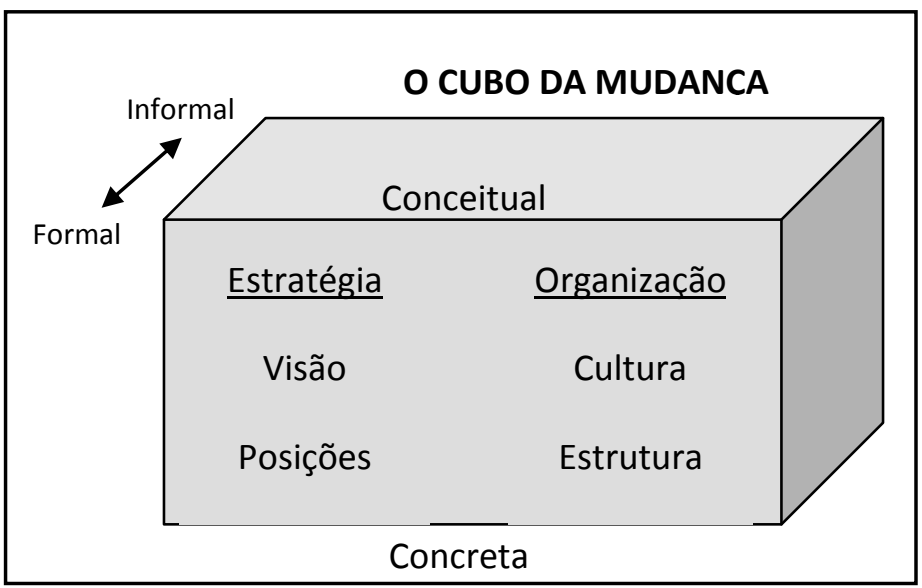

Figura 1 O Cubo da Mudança (Mintzberg et all, 2006)

Autores como Santos e Pereira (2012) já constataram que a universidade tem características estruturais e operacionais mais complexas que outras organizações. O modelo de Mintzberg pode traduzir a complexidade da mudança em organizações educacionais e sua implicação nas diversas dimensões organizacionais. Para proceder a análise dos dados com base no referencial teórico utilizou-se a metodologia de pesquisa apresentada a seguir.

\section{METODOLOGIA}

Esta pesquisa pode ser caracterizada como qualitativa, pois pretende utilizar uma série de técnicas interpretativas que procurarão "[...] descrever, decodificar, traduzir e entender o significado de certos fenômenos que ocorreram com relativa naturalidade em uma organização" (COLLIS e HUSSEY, 2005, p. 145). A principal metodologia utilizada foi o de estudo de caso, caracterizada como um exame extensivo de um único exemplo de um fenômeno de interesse. Para Bonoma (1985) 'ele deve ser 'formado' para ser sensível ao contexto no qual o comportamento gerencial acontece" (apud COLLIS e HUSSEY, 2005, p.73). Segundo a tipologia de Scapens (1990), a pesquisa pode ser caracterizada mais precisamente como estudo de caso descritivo-explanatório, ou seja, a teoria existente é usada para descrever as práticas e para entender e explicar o que está acontecendo (apud COLLIS e HUSSEY, 2005).

Outra característica do estudo de caso identificada por Yin (2005) e que pode ser relacionada ao presente estudo é que o objetivo da pesquisa não será somente explorar certos fenômenos, mas também entendê-los num determinado contexto. 
O contexto em que ocorreu o processo de mudança - uma universidade pública - e a complexidade do processo contribuíram para a escolha intencional da amostra. A razão da escolha pode-se justificar pelo fato de ser ela uma das maiores universidades públicas do país, constituída por uma história que se confunde com um período do próprio Estado de São Paulo no qual está instalada, uma cultura consolidada e diferenciada e a possibilidade de suas experiências servirem como modelo para organizações mais novas.

Os sujeitos da pesquisa foram cinco dos dez primeiros coordenadores dos dez cursos da nova unidade, criada há cerca de oito anos. Os coordenadores ficaram em média quatro anos na função e foram os responsáveis pela implantação do projeto pedagógico e pela seleção dos primeiros professores e alunos. Dos cinco, três possuíam mais de vinte anos de experiência no ensino superior e o mesmo tempo na Universidade. Dois possuíam menos de dez anos de experiência no ensino superior e estavam há menos de cinco anos na Universidade.

Os coordenadores dos cursos foram submetidos a entrevistas semi-estruturadas, tendo sido realizadas um total de cinco entrevistas, sendo três gravadas e transcritas e duas registradas por meio de anotações. O objetivo era identificar ideias, valores e crenças dos gestores em relação à implantação do projeto. Buscaram-se, em seguida, congruências e incongruências entre os principais indicadores de mudança no projeto pedagógico e o que os gestores de fato praticavam, questão não identificada como objetivo inicial, mas que acabou por revelar-se importante.

A técnica utilizada para a análise dos dados primários foi a de análise documental, segundo Bardin (1979), sendo utilizada a abordagem temática para a compreensão do nível de desenvolvimento dos esquemas interpretativos dos gestores.

Para a análise da mudança implicada no projeto da nova unidade também foram utilizados dados secundários sobre o setor educacional, sobre a história da Universidade e sobre o projeto da unidade, em especial, livros, artigos, atas que relatam o processo de formulação do projeto. A partir da análise desses documentos foi possível estabelecer alguns indicadores de mudança segundo a perspectiva de Mintzberg et al. (2006). A partir dessas fontes primárias e secundárias utilizou-se a técnica de triangulação para a análise e interpretação dos dados 


\section{ANÁLISE DOS DADOS}

A análise dos dados da pesquisa está dividida em duas partes. Primeiramente, o projeto da nova unidade é detalhado, sendo destacados os aspectos inovadores a partir de seus princípios e diretrizes acadêmicos, relacionado-os aos componentes do cubo da mudança de Mintzberg et al. (2006) apresentados no referencial teórico. Em seguida, são analisados os esquemas interpretativos dos gestores, buscando-se identificar valores e crenças individuais e coletivos.

\subsection{ANÁLISE DO PROJETO DA NOVA UNIDADE UNIVERSITÁRIA}

Formada a primeira Comissão Central para estudo e elaboração dos princípios e diretrizes gerais da nova unidade, após certo período de tempo, foi apresentado um relatório inicial "o qual indicava a concepção de um projeto inovador que preservasse as qualidades indiscutíveis da Universidade, embora modificando alguns elementos passíveis de aperfeiçoamento, tanto do ponto de vista acadêmico como de estrutura e gestão" (KRASILCHIK, 2005, p. 84).

A afirmação ressalta alguns aspectos importantes para a compreensão do processo de mudança. A nova unidade, apesar de se constituir em um projeto inovador, não romperia com a tradição da Universidade e com as suas qualidades reconhecidas. Não era o caso de se fazer outra universidade, com outras características. Seria a mesma com 'aperfeiçoamentos' acadêmicos, estruturais e na gestão.

As principais diretrizes deste primeiro relatório indicavam os seguintes pontos:

- Deveriam ser criados cursos inexistentes em outros campi;

- A nova unidade deveria pautar-se pela inovação e zelar pela qualidade do ensino, da pesquisa, da extensão e de serviços, que confere padrão de excelência à Universidade;

- Deveria atender à expansão do ensino médio e ampliar a diversidade de alunos na Universidade;

- Deveria ser uma escola em que "convivessem professores e pesquisadores de várias áreas em atmosfera de produção, disseminação e aplicação de conhecimento, sem fronteiras como barreiras" (KRASILCHIK, 2005, p. 85);

- Os cursos deveriam oferecer aos alunos uma formação rigorosa e visão ampla da sociedade em que atuam como indivíduos, profissionais e cidadãos. 


\title{
MUDANÇA ESTRATÉGICA E PROCESSO DE INSTITUCIONALIZAÇÃO EM UMA UNIVERSIDADE: O DESENVOLVIMENTO DE ESQUEMAS INTERPRETATIVOS ENTRE OS GESTORES \\ DOI: http://dx.doi.org/10.5007/1983-4535.2014v7n3p206
}

Para atingir esses objetivos, os membros da Comissão afirmavam que:

\begin{abstract}
O primeiro ano básico deveria incluir, além das disciplinas introdutórias de cada curso, disciplinas gerais que propiciassem visão aberta e cosmopolita dos grandes temas contemporâneos, e atividades de trabalho coletivo para o desenvolvimento de uma postura permanente de investigação (KRASILCHIK, 2005, p. 85).
\end{abstract}

As diretrizes implicam claros indicadores acadêmicos, estruturais e de gestão. Academicamente, a pesquisa é o centro das atividades. Orienta e organiza o ensino, a extensão e os serviços da nova unidade. Porém, busca-se uma pesquisa integrada, na qual a fronteira entre as ciências esteja mais permeável a trabalhos conjuntos entre as áreas. Esperase que a convivência e o diálogo entre gestores, professores, alunos e comunidades constituam-se os fundamentos do comportamento das pessoas. O aperfeiçoamento da estrutura e da gestão busca fomentar esse processo.

Convivência e diálogo implicam em espaços estruturados para esse propósito e que com o tempo institucionalizem-se como práticas indispensáveis ao funcionamento da nova unidade. Isso exige, entre outras questões, presença de gestores, professores e alunos na nova unidade, calendário permanente de reuniões e debates sobre questões importantes, formas inovadoras de integrar pesquisadores de áreas diferentes, articulação com segmentos das comunidades vizinhas e participação destas nos processos acadêmicos e organizacionais.

O modelo epistemológico adotado no projeto tem como pressuposto que "a ação e o protagonismo dos seres humanos na construção, produção e transformação da realidade passam a serem vistos como uma forma mais adequada para compreender o papel que os estudantes e os professores devem desempenhar na relação entre ensino e aprendizagem" (ARANTES, 2005, p. 103). O currículo está estruturado em três dimensões: o problema, os conteúdos e o grupo. Essas dimensões são trabalhadas por meio da abordagem de Resolução de Problemas articulada com a Aprendizagem Baseada em Projetos, que constituem a essência do ciclo básico da nova unidade.

A abordagem epistemológica e a estrutura curricular reforçam o protagonismo dos alunos e professores em uma perspectiva coletivista, focada na pesquisa integrada e interdisciplinar, necessitando para tanto romper com certos tradicionalismos presentes na universidade.

Para Araújo esse rompimento depende da "articulação entre o projeto (estratégia) e as ações de planejamento e gestão operacional que garantam as condições físicas e humanas necessárias à consecução das metas almejadas" (ARAUJO, 2005, p. 135). O autor destaca a 
articulação que houve entre a equipe de gestores e funcionários, criada antes do início do funcionamento da nova unidade, e a demanda dos projetos novos oriundos dos cursos criados, resultando em duas frentes de atuação: articulação entre a ocupação física e o projeto acadêmico e a organização da ocupação dos espaços. Também é destacada a experiência de "incubação" do funcionamento administrativo da nova unidade antes de sua inauguração, em ambiente externo à unidade, funcionando como um laboratório de aprendizagem em serviço.

No aspecto tecnologia foi adotada, como ferramenta de apoio ao ensino, o CoL (Cursos on-Line), um sistema gerenciador de material didático que permite aos professores gerenciar seus cursos de maneira simples e integrada, por meio da web. "Sua utilização teve como objetivo criar um ambiente acadêmico inovador e rico e trouxe possibilidades de intercâmbio entre docentes e discentes" (ARAUJO, 2005, p. 145).

$\mathrm{O}$ arquitetônico inicial da nova unidade seguiu, segundo os documentos pesquisados, as demandas dos cursos, mas de acordo com os princípios acadêmicos e organizacionais da nova unidade. Neste aspecto, não foram construídos laboratórios exclusivos para um determinado curso ou para um pesquisador individualmente. $\mathrm{O}$ projeto físico deveria seguir o projeto acadêmico.

Elaborado o projeto acadêmico e organizacional, coube aos primeiros coordenadores dos cursos a implementação da nova estratégia. São analisados a seguir os principais valores e as crenças dos gestores, definidos a partir das entrevistas em profundidade.

\subsection{ANÁLISE DOS ESQUEMAS INTERPRETATIVOS DOS GESTORES}

Do cruzamento entre as diretrizes, princípios e objetivos do projeto da nova unidade com os temas sobressaídos dos esquemas interpretativos dos gestores nas entrevistas foi elaborado um quadro síntese do comportamento gerencial. A seguir é apresentada esta síntese e comentada. 
MUDANÇA ESTRATÉGICA E PROCESSO DE INSTITUCIONALIZAÇÃO EM UMA UNIVERSIDADE: O DESENVOLVIMENTO DE ESQUEMAS INTERPRETATIVOS ENTRE OS GESTORES

DOI: http://dx.doi.org/10.5007/1983-4535.2014v7n3p206

\begin{tabular}{|c|c|c|c|c|c|}
\hline TEMAS & E1 & E2 & $\mathbf{E 3}$ & $\mathbf{E 4}$ & E5 \\
\hline Projeto Pedagógico & Guia & Guia & Guia com ajustes & Guia com ajustes & Guia \\
\hline Estrutura & Estratificada & Linear & Linear & Linear & Linear \\
\hline Tomada de decisão & Centralizada & Descentralizada & Descentralizada & Descentralizada & Descentralizada \\
\hline Participaçãa & Restrita & Ampla & Restrita & Ampla & Ampla \\
\hline Autonomia & $\begin{array}{l}\text { Depende do alcance } \\
\text { das metas }\end{array}$ & Ampla & Ampla & Ampla & Ampla \\
\hline Aprendizado & individual & Individual & Individual & Individual & Individual \\
\hline Relação com o ambiente & Proativo e reativo & Reativo & Proativo e reativo & Proativo e reativo & Proativo e reativo \\
\hline Seleção & Etapa fundamental & Etapa fundamental & Etapa fundamental & Etapa fundamental & Etapa fundamental \\
\hline Treinamento & Não prioritário & Não prioritário & Não prioritário & Não prioritário & Não prioritário \\
\hline Avaliação & Específica/geral & Geral & Geral & Geral & Geral \\
\hline Tecnologia & Pouca ênfase & Pouca ênfase & Pouca ênfase & Pouca ênfase & Pouca ênfase \\
\hline Utilização dos espaços & Não plenamente & Não plenamente & Não plenamente & Não plenamente & Não plenamente \\
\hline Função do gestor & Bem definida & Conflito & Bem definida & Conflito & Conflito \\
\hline
\end{tabular}

Quadro 1 Síntese dos Esquemas Interpretativos dos Gestores 


\section{MUDANÇA ESTRATÉGICA E PROCESSO DE INSTITUCIONALIZAÇÃO EM UMA UNIVERSIDADE: O DESENVOLVIMENTO DE ESQUEMAS INTERPRETATIVOS ENTRE OS GESTORES \\ DOI: http://dx.doi.org/10.5007/1983-4535.2014v7n3p206}

O Projeto Pedagógico assume um valor de guia das ações para todos os entrevistados, porém de forma diferenciada. Para E1, muitas diretrizes não estão sendo realizadas, podendo prejudicar o caráter inovador do projeto, no futuro. Para E2, a proposta deve ser seguida, "mas depende de cada professor e de cada aluno em enxergar o que é válido para o futuro profissional de cada um". Para E4 as mudanças no projeto original correspondem a processos de ajustes necessários em razão do funcionamento efetivo dos cursos.

A estrutura sem a presença dos departamentos trouxe demandas novas aos coordenadores de cursos. Na visão de E1 e E3 isso não é problemático, mas E1 demonstrou total controle sobre a condução das atividades do curso, valorizando o colegiado, porém trabalhando politicamente na tomada de decisão. E2, E4 e E5 desenvolvem uma coordenação mais linear, com a formação de comissões para definição e coordenação de projetos, sendo que E2 demonstrou pouca atenção aos processos políticos envolvidos na tomada de decisão. A participação tem valor central para E2, E3, E4 e E5, ocorrendo principalmente por meio de comissões de extensão, pesquisa e de revisão de projetos pedagógicos. Porém, nada é determinado diretamente pelo gestor, o que muitas vezes tem sobrecarregado alguns professores e os próprios gestores em razão destes acabarem tendo de participar em várias comissões, ao mesmo tempo.

A autonomia dos professores é um valor comum entre os entrevistados, mas E1 condiciona-a ao alcance das metas estabelecidas por ele no início de cada semestre. Para os demais entrevistados, mesmo nos primeiros anos na universidade, o professor deve ter liberdade de atuar como bem entender. Pois, segundo E2, "para a universidade, eles já ingressam prontos para atuar”.

O controle sobre as atividades dos professores da nova unidade segue a tradição deste tipo de organização, sendo caracterizado no nível baixo. A exceção foi E1 que apresentou propostas e critérios, segundo ele, bastante efetivos de acompanhamento das atividades docentes.

Para todos os entrevistados destaca-se a crença de que o processo de seleção é fundamental para garantir o ingresso de profissionais com perfis mais adequados ao trabalho na nova unidade. Este foi um dos aspectos mais destacados por E1 quando de sua entrevista. Além da elaboração dos editais com os critérios e o perfil desejado dos professores, todos os gestores entrevistados participaram de várias bancas de seleção. 
Não ficou evidente pelas entrevistas e documentos analisados, um projeto específico para o aprendizado individual e coletivo ou para a estruturação do conhecimento na nova unidade. E2 demonstrou preocupação com a questão e defendeu a participação de todos os ingressantes em projeto de capacitação desenvolvido no âmbito geral da universidade. Nenhum dos entrevistados apresentou ações relacionadas diretamente com o treinamento de professores. Segundo a descrição do momento de acolhimento dos novos professores, os gestores apresentam, em linhas gerais, as diretrizes do projeto da nova unidade e o projeto pedagógico dos cursos. Para E5, o ingresso, no inicio do projeto era mais bem organizado, com uma imersão de todos os ingressantes em local diferenciado que propiciava uma maior integração entre todos os envolvidos. Todos citaram o ciclo básico e a disciplina de resolução de problemas como concentradores da atenção no aspecto de treinamento e desenvolvimento dos novos professores.

A relação da gestão dos entrevistados com o ambiente é proativa ou reativa, dependendo dos fatores ambientais relacionados. A gestão da nova unidade é proativa quando todos os cursos desenvolvem seus projetos de extensão e mantém uma relação muito próxima com as comunidades próximas. Há uma preocupação com a inserção dos egressos, sendo mantidos contatos freqüentes com empregadores privados e públicos. Os entrevistados salientaram, porém, a dependência dos cursos em relação às políticas do ensino superior, em especial, as especificadas pelo Conselho Estadual de Educação, assim como, a dependência financeira da nova unidade em relação à Reitoria e, por conseguinte, ao Governo do Estado. Persistem também as características reativas das ações dos gestores ao utilizarem os mesmos processos de avaliação e de desenvolvimento de pessoal adotados na universidade, apesar destes apresentarem elementos contraditórios com o projeto da nova unidade.

A avaliação de desempenho dos professores segue uma orientação geral de toda a Universidade, de acordo com critérios estabelecidos pela Pró-Reitoria de Graduação. E1 citou uma forma específica de avaliação dos professores de seu curso e deu bastante destaque ao acompanhamento da avaliação periódica que os professores são submetidos no âmbito da Universidade.

Sobre o uso de tecnologia por parte da gestão e dos professores pouca ênfase foi dada ao longo das entrevistas, sendo que apenas E5 destacou o uso de email para comunicar-se melhor com os professores e alunos. 


\section{MUDANÇA ESTRATÉGICA E PROCESSO DE INSTITUCIONALIZACCÃO EM UMA UNIVERSIDADE: O DESENVOLVIMENTO DE ESQUEMAS INTERPRETATIVOS ENTRE OS GESTORES \\ DOI: http://dx.doi.org/10.5007/1983-4535.2014v7n3p206}

A utilização dos espaços arquitetônicos da nova unidade na opinião dos entrevistados não é plena, mas as justificativas de cada um sobre o uso desses espaços são diferentes. Para E1, os professores precisam se dedicar mais aos cursos. "Eles não ficam na unidade". Para E2, no momento em que for possível realizar pesquisas nos laboratórios (ainda a serem construídos) os professores ficarão na unidade. Para E3 a utilização é parcial, não parecendo ser esta uma preocupação central para ele. Para E5, no início, a proximidade era muito maior em razão do tamanho da unidade, da possibilidade constante de se encontrarem na sala dos professores, de dividirem o mesmo computador, o que não mais acontece hoje em dia.

Com exceção de E1 e E3, os demais apresentaram conflitos em relação ao papel que deve ter o gestor acadêmico na unidade. Em vários momentos da entrevista este foi um aspecto bastante ressaltado sendo comum para os entrevistados a necessidade de rever a estrutura para melhor adequá-la à situação atual. Perguntados sobre se essa revisão incluiria o retorno dos departamentos todos foram unânimes na negativa.

A partir da análise do projeto da nova unidade e dos valores e crenças manifestados pelos gestores é possível chegar às conclusões, de acordo com os objetivos da pesquisa.

\section{CONCLUSÕES}

A análise das ideias, valores e crenças dos gestores de nível médio permitiu compreender de forma mais aprofundada os processos e sentidos dados às ações desenvolvidas na nova unidade. Percebeu-se que as temáticas destacadas no referencial teórico, na análise documental e nas entrevistas apresentam diferentes formas de se efetivarem na prática. Os gestores pensam e agem de diferentes maneiras quando enfrentam problemas na nova unidade. Apesar do projeto estratégico da unidade constituir-se um guia para todos os entrevistados, não há um claro alinhamento deste com as ações tomadas pelos coordenadores em seu dia-a-dia.

Em razão disso, não foi possível identificar um padrão ou modo de dirigir específico da nova unidade como também, não parece ser esta uma das prioridades dos gestores no momento atual.

Como congruências identificadas é possível destacar:

1. A importância dada pelos gestores ao projeto pedagógico da nova unidade, a consciência de seus princípios e suas diretrizes principais; 
2. A compreensão do papel fundamental dos professores e alunos na implementação do novo projeto.

Como incongruências destacam-se:

1. Não foi uma preocupação dos elaboradores e executores iniciais do projeto a construção de um padrão de gestão capaz não de impedir as diferenças, mas de destacar as semelhanças em processos e ações tomadas pelos futuros gestores da unidade;

2. A falta do planejamento de ações de treinamento e desenvolvimento dos professores, principalmente após o primeiro ano.

3. A ausência de efetiva integração entre as pessoas o que tem impedido um maior diálogo interdisciplinar, principalmente após o primeiro ano.

4. A incompreensão do papel central dos coordenadores dos cursos e suas novas atividades.

Em uma avaliação preliminar, mas já fruto de uma maior compreensão por parte do pesquisador de todo o processo de formulação e implementação do projeto da nova unidade, pode-se inferir um equívoco que pode levar a uma implementação parcial ou à modificações em aspectos diferenciais do projeto. Este equívoco pode estar configurado no número elevado de cursos implantados ao mesmo tempo e em áreas muito diversificadas. Isto pode ser constatado, pois com exceção de atividades desenvolvidas no primeiro ano, são poucas as atividades em que ocorrem a integração e o diálogo, base de todo o projeto estratégico da nova unidade, fruto talvez das diferenças culturais comuns aos profissionais envolvidos na implementação.

Neste caso, seleção e desenvolvimento de pessoas não podem estar dissociados. Os novos professores trazem métodos de trabalho e condições comuns as suas práticas profissionais. Tornam-se uma das fontes de pressão para a conformação estrutural e processual. Sem um movimento no sentido inverso, provavelmente o tempo se encarregará de tornar semelhantes as práticas da nova unidade aos processos já institucionalizados das demais unidades da Universidade, acabando por uniformizar a estrutura e retirando, gradativamente, os aspectos mais inovadores e diferenciadores do projeto estratégico da nova unidade.

Para a correção desse aspecto central, uma melhor compreensão das funções dos coordenadores (gestores) é fundamental. Começando pela definição de qual é o papel do 
coordenador de curso na nova unidade. Em seguida, mediante processo planejado de discussão de problemas e suas possíveis soluções, pode ser possível ir criando modos de interpretação da realidade organizacional mais sintonizados entre os gestores. A partir disso, será possível definir com clareza os princípios, as orientações e as ações capazes de ordenar um padrão ou modo de gestão característico da nova unidade, fato ainda não constatado na pesquisa.

Para responder a pergunta inicial formulada por Holm (1995), a institucionalização da mudança por meio da implementação de um novo projeto estratégico requer a definição de novas estruturas e de novos processos em conjunto, em interação, e em um lento, mas permanente processo de desenvolvimento de esquemas interpretativos coletivos entre os envolvidos.

\section{REFERÊNCIAS}

ARANTES, Valéria. Articulação interdisciplinar entre conhecimentos científicos gerais: o Ciclo básico da USP Leste. In: GOMES, C.B. (Org.). USP Leste: A Expansão da Universidade - do Oeste para Leste. São Paulo: Edusp, 2005.

ARAUJO, Ulisses F. Entre o acadêmico e a gestão universitária: a Construção de espaços, tempos e relações da USP Leste. In: GOMES, C.B. (Org.). USP Leste: A Expansão da Universidade - do Oeste para Leste. São Paulo: Edusp, 2005.

BARDIN, Laurence. Análise de Conteúdo. São Paulo: Ed. Setenta. 2008.

BERGER, Peter; LUCKMANN, Thomas. A construção social da realidade. Petrópolis: Vozes, 2008.

CANÁRIO, Rui. Estabelecimento de ensino: a inovação e a gestão de recursos educativos. In: NÓVOA, A. (coord.). As organizações escolares em análise. Lisboa: Dom Quixote, 1992.

COCHIA, Camilla B. R.; MACHADO-DA-SILVA, Clóvis L. Ambiente, interpretação e estratégia em organizações paranaenses dos setores de vestuário e alimentos. Revista de Administração Contemporânea (RAC). Edição Especial, p. 11-35, 2004.

COLLIS, Jill; HUSSEY, Roger. Pesquisa em Administração. Porto Alegre: Bookman, 2005.

CRUBELLATE, João Marcelo. Parâmetros de qualidade de ensino superior: análise institucional em IES privadas do Estado de São Paulo. 2004. Tese (doutorado). Fundação Getúlio Vargas. Escola de Administração de Empresas de São Paulo.

DAFT, R.I.; WEICK, K. Organizações como sistemas interpretativos: em busca de um modelo. In: CALDAS, M.P; BERTERO, C.O. (Orgs.). Teoria das organizações. São Paulo: Atlas: 2007. 
DEMO, Pedro. Desafios modernos da educação. Petrópolis: Vozes, 1995.

DIMAGGIO, P. J.; POWELL, W. W. Jaula de ferro revisitada: isomorfismo institucional e racionalidade coletiva nos campos organizacionais. In: CALDAS, M.P; BERTERO, C.O. (Orgs.). Teoria das organizações. São Paulo: Atlas: 2007.

FLEURY, M. T. L.; FISCHER, R. M. Cultura e Poder nas organizações. São Paulo: Ed. Atlas, 2007.

GIDDENS, Anthony. A Constituição da sociedade. São Paulo, Martins Fontes, 2003.

HININGS, C. R.; GREENWOOD, R. The dynamics of strategic change. New York: Basil Blackwell, 1987.

HOLM, Petter. The dynamics of institutionalization: transformation processes in Norwergian Fishenes. Administrative Science Quarterly, 40, 1995, p. 398-422.

HUBERMAN, A. M. Como se realiza a mudança em educação: subsídios para o estudo do problema da inovação. São Paulo: Cultrix, 1973.

KLASILCHIK, Mirian. Gestão - desafios e perspectivas. Revista USP. São Paulo, n. 78, p. 22-31, junho/agosto, 2008.

LIMA, Licinio. A Escola como organização educativa. São Paulo: Cortez, 2008.

MACHADO-DA-SILVA, C. L.; FONSECA, V.S.; CRUBELLATE, J. M. Estrutura, agência e interpretação: elementos para uma abordagem recursiva do processo de institucionalização. Revista de Administração Contemporânea, RAC. Edição Especial, 2005, p. 09-39.

MACHADO-DA-SILVA, C.L.; FONSECA, V. S.; FERNANDES, B. H. R. Um modelo e quatro ilustrações: em análise a mudança nas organizações. In: XXIII Encontro Anual da ANPAD (1999: Foz do Iguaçu). Anais: Foz do Iguaçu: ANAPAD, CDROM, 1999.

MINTZBERG, H.; LAMPEL, J.; QUINN, J.B.; GHOSHAL, S. O Processo da estratégia: conceitos, contextos e casos relacionados. Porto Alegre: Bookman, 2006.

RANGEL, Suzana. Documento de trabalho. Encontro de Administração Superior. Belém: UEPA, 2002.

RODRIGUES, L.C.; RIEDI, A. M.; RISCAROLLI, V.; MACCARI, E. A. Plenitude institucional no ensino superior: uma análise das universidades do sistema ACAFE. VI

Colóquio Internacional sobre Gestão Universitária na América do Sul. Blumenau, SC, 2008, Anais.

SANTOS, A. M.; PEREIRA, M. F. Universidade e modificação organizacional: do modelo burocrático à organização intensiva em conhecimento. Revista GUAL, v.5, n.1, 2012, p. 0127. 
TENBRUNSEL, A.E.; GALVIN, T.L.; NEALE, M. A.; BAZERMAN, M.H. Cognições em Organizações. In: CLEGG, S.; HARDY, C.; NORD, W. (Ed.). Handbook de Estudos Organizacionais, v. 3. São Paulo: Editora Atlas, 2004.

YIN, Robert K. Estudo de Caso: planejamento e métodos. Porto Alegre; Bookman, 2005.

VASCONCELOS, Flávio C. de. Estratégia empresarial e construção social da realidade: o caso da Internet no Brasil. In: XXVI Encontro Anual da ANPAD (2002; Salvador). Anais: Salvador: ANPAD, CDROM, 2002 